\title{
Evaluation of Pathogenic Bacterial Contaminants in Road Side African Salad (Manihot Esculenta) and Their Effect in the Gastro Intestinal System of Subjects in Enugu Nigeria.
}

\author{
Oguwike F. N, Olisah M.C, Nwadighoha A.N, Emenuga V.N, Ezekwueme E.N \\ Department of physiology, Faculty of Basic medical sciences, Anambra state university Uli, Anambra state, \\ Nigeria. \\ Department of medical Biochemistry, Faculty of Basic medical sciences, Anambra state university Uli, Anambra \\ state. \\ Department of Public Health, Imo State University, Owerri. \\ Department of medical lab sciences, Faculty of Health science and technology. University of Nigeria Enugu \\ campus, Enugu Nigeria . \\ Department of medical lab sciences, Faculty of health sciences and technology, Nnamdi Azikiwe university \\ Teaching hospital Nnewi,, Anambra state Nigeria
}

\begin{abstract}
African salad made from cassava tubers (Manihot esculenta) is a special delicacy enjoyed by both the poor and the rich in our region. This study evaluated the pathogenic bacterial contamination in Roadside African salad and their effect in the gastro intestinal system of man. The study was conducted to note the percentage presence of these contaminants (staph. aureus, salmonella, shigella and Entaemoeba) in African salad juice and also the age group that these organisms infect most in females who enjoy this delicacy alot. 40 subjects were selected at age range (3-35yrs) and grouped in four(4) groups; Group A (control l 0), are apparently healthy subjects who do not eat the delicacy, Group B (10) are females in range of 3-15yrs, Group c (10) are females in the range of 16-25yrs and Group $D(10)$ are females in the age range of 26-35yrs. These are the test groups that consume this delicacy hawked about for one week (7 days) and came up with reports of running stool, fatigue, aches and rising titre of febrile reaction. The result of the study showed that the commonest pathogenic contaminant in African salad is salmonella (80\%) and it occurs more often in adult women of 26-35yrs(p<0.05); E. histolytica (50\%), shigella, staph. (70\%) Aureus (30\%) and normal flora (60\%). Contraction of E. histolytica from consumption of African salad occur more in groups $C$ and $D(p<0.05)$ while staph. aureus occurred with equal percentage range in groups $C$ and $D(p<0.05)$. It could be deduced from this study that consumption of African salad from road-side hawkers could be unsafe and may give chances to contraction of bacterial pathogens.

Key word: African salad, pathogens, Roadside hawkers, and contaminations.
\end{abstract}

\section{Introduction}

Cassava (Manihot esculenta crant) is a major source of carbohydrate particularly for low-income individuals. At present, cassava is a major source of food for 800 million people (Nweke, 1996). This species 'Manihot esculenta' is a native to the north east of Brazil but spread throughout the South American continent. The plant was spread by Portuguese and Spanish explorers to most of the West Indians, African and Asia including the Philippines and Taiwan, but now cultivated worldwide (Wikipedia, 2013). In Brazil, the plant (cassava) is named "Mandioca", while its starch is called "Tapioca". The cassava plant has either red or green branches with blue spindle on them.

In Nigeria, the easterners (Ibos) cherish cassava plant and its products a lot. The tubers are called various names such as 'Jiakpu', 'Jiakwu', (Igbo). The tubers are used to prepare various delicacies such as Abacha or African salad, 'Abacha Nkpo', 'Abacha mmiri' or foo foo. They are being hawked by low income groups as source of making ends meet. Women and children like this African salad a lot but the ugly part of it is the unhygienic preparation of the African salad delicacy for sale to the general public and sometimes, it is prepared by typhoid carriers.

The unhygienic per se, refers to the exposure of the sliced cassava tubers in streams for days, thus exposing it ignorantly to virulent bacteria that flow in streams which sometimes cause amoebic dysentery and typhoid fevers in the consumers. Other foods during their processing are not exposed to streams it is done to sliced cassava. They do not get contaminated and they are properly cooked by boiling in water unlike African salad. 


\section{FOOD VALUES OF CASSAVA TUBERS:}

Cassava tubers are rich in carbohydrates, mainly starch, and are a major source of energy (food safety network, 2005) with the exception of sugar cane:- cassava is the highest source of carbohydrates. Cassava tubers are therefore deficient in protein, fat and some minerals and vitamins. The nutritional value is less than that of cereals, legumes and some other root such as yam. Cassava leaves contain more proteins than the tubers but they lack the essential amino acid methionine. The leaves are used for human consumption and animal feed.

\section{CHEMICAL CONTENT OF TUBERS:-}

Cassava contains the potential toxic compounds such as cyanogenic glycosides, starch, glycosides, water, sugar, fibers. The accidental contraction of food pathogens by consumers as a result of improper and unhygienic preparation of this delicious delicacy is what promoted my curiosity to evaluate the bacterial contamination of this delicacy "African salad" and its effect in the gastrointestinal tract. Hence the aim of this study is to evaluate the various pathogens that can be possibly contracted from consuming this meal bought from roadside hawkers. The following organisms are commonly seen along with cassava roots; Enterobacteriacal spore forming bacteria, Acinetobacter spp, Micrococcus specie, Enterobacteriacae, Pseudomonas, Moraxella and Aeromonas spp. These are normal flora. Other bacteria of medical importance that can be seen in cassava juice in little quantity are Bacillus cereus and Listeria monocytogenes (Dasse et al, 2007). When these organisms especially Staphylococcus aureus and Bacillus cereus occur in great quantity on the cassava root, they pose a serious threat to health if consumed along with the cassava. Organisms that can be contracted accidentally during consumption of this delicacy called African salad which are waterborne organisms are Salmonella shigella, Entaemoeba- histolytica, cholera and amoebic pathogens.

Salmonella typhi and Salmonella paratyphi-A, B, and $C$ causes enteric fevers or bacteraemia (Bello, 1994). Man is said to be the prime source of these infective agents usually as carrier causes, while the mode of transmission is through water, food, formites and faecal oral route. Typhoid fever, cholera, dysentery are spread by victims. Carriers who pass stool indiscriminately into our streams, leaving their stool exposed to flies failing to wash their hands after going to toilet, if such person is employed as a cook of the African salad delicacy, he will be a direct source of the spread of the infections.

The gastrointestinal system is the avenue through which nutritive substances, vitamins, minerals and fluids enter the body (Oguwike, et al 2013). Protein, fats and complex carbohydrates are broken down into absorbable units mainly in the small intestine. The products cross the mucosa and enter the lymph or the blood. This entry is called absorption. The undigested bacteria (pathogenic and nonpathogenic) lodge in the large intestine, multiply and begin to alter the healthy functions of the organ which results to running stool (diarrhea) or dysentery and sometimes enteric fevers.

\section{Materials And Methods:-}

SUBJECTS:

The subjects consist of non-consumers (group A, 10 subjects) mainly females. Group B are children 10 subjects (3-15 years) who eats the delicacy once in a while, Group C consists of ten (10)subjects (16-25 years), Group D (10 subjects) Chronic consumers (ages 26-35 yrs) completed the study groups.

\section{EXPERIMENTAL DESIGN:-}

Female subjects who are fond of this delicacy were used for this study. They were given the already prepared roadside African salad for several days (7 days). Those that ate the Abacha (African salad) are those in the groups B (3-15 years), C (16-25 years) and D (26-35 years). The control subjects are those that do not eat African salad. All the subjects that came up with all the clinical report of running stool febrile antigen reactionwere selected and used for the study to note the effect in the gastrointestinal system. The presence of bacterial pathogens were noted in the roadside African salad by taking and culturing the juice into culture plates and taking the readings after 24-48 hours incubation.

\section{PREPARATION OF AFRICAN SALAD OR ABACHA:-}

Eighty matured cassava tubers were peeled, washed and boiled (half done) in boiling water. It was sliced into tiny long sizes and packed in a basket. They were finally kept in the river or stream for 48 hours (Ucheonye, 2012). Then they were washed in the stream and brought home for preparation of the African salad. $1500 \mathrm{~g}$ was measured and used for the preparation. Into a bowl was placed $500 \mathrm{ml}$ of lukewarm water. $2 \mathrm{~g}$ of potash salt was dissolved in it coupled with $300 \mathrm{ml}$ of fresh oil, 1 cup of crayfish, pieces of green pepper, 5.0 grams of salt, melon seed (ogiri-igbo) pieces of animal kin (canda), 2 bundles of garden egg vegetables (anara) were mixed in it. Finally the sliced cassava tubers were poured into it and properly turned around in the bowl using a big kitchen spoon, making a uniform mixture, bringing out an attractive odor. 


\section{PREPARATION OF CASSAVA JUICE:}

Juice from cassava (African salad) was extracted by fruit grinding centrifugal machine and steamsterilized. The juice was diluted in Brain heart infusion (BHI) Broth (Merck) to give final concentrations of 25, $50 \%$ and $75 \%$ cassava juice (Desse and Taye 2007) that was used for culture.

\section{DETECTION OF FOODBORNE PATHOGENS IN AFRICAN SALAD PREPARED BY ROADSIDE FOOD VENDORS:-}

The juice from the sliced and processed cassava tubers to be used for preparation of African salad by hawkers were collected and examined for identification and detection of pathogens using the following methods:

Salmonella: To identify salmonella and enterobacterial organisms. From the appropriate dilutions $0.1 \mathrm{ml}$ volumes were taken, spread plated in duplicates into violet red glucose agar (oxoid) plates and incubated at 30$32^{\circ} \mathrm{c}$ for 24 hours.

Staphyloccoci: To identify Stapyloccocus aureus, appropriate dilutions were spread-plated in duplicate plates of Manitol salt Agar (Oxford) and incubated at $30-32^{\circ} \mathrm{c}$ for $48-72$ hours. Ten colonies from countable plates were picked and slide and tube coagulase test was done (Baker and Silverton, 1985).

Shigella: To identify shigella, fluid samples from the cassava extracted fluid were plated into cled medium and incubated for 24 hours. Shigella organism will be identified by its peculiar characteristic swarming in the plate.

Aerobic Mesophilic Bacteria: Samples were further diluted in sterile tap water and volume of $0.1 \mathrm{ml}$ of appropriate dilutions were spread-plated in duplicates on pre-dried surfaces of plate count agar (PC: Merk). Colonies were counted after incubation at 30 to $32^{\circ} \mathrm{c}$ for $48-72$ hours.

Selection of subjects for study: The control subjects consist of apparently healthy subjects who tested negative and free from salmonella infection (Titre 1:20), entamobiasis, shigellosis and staphylococci infections. They are group A subjects consisting of 10 subjects.

The experimental subjects consists of Group B (10 female children of 3-15 years), Group C (10 young females of age range 16-25 years) and group D (10 adult females of age range 26-35 years) and showed positive when screened for the presence of salmonella typhi (using blood samples and rising titre1:320), E.histolytica (using stool samples and detection of the organism) and shigella (using stool samples for culture) staph aureus (using sample). A total of thirty (30) sick subjects and ten (10) apparently healthy female subjects were used for this study.

Stool culture of samples for test: was carried out by method of culturing technique as described in Baker and Silverton 1985.

Stool analysis test: was done by wet preparation method as described by Crewe (1977).

Widal test: was carried out by method of Antigen -antibody reaction as described by Baker Silverton, 1985 using serial-dilutions.

Urine culture tests: were done by method of Baker et al, 1985. Coagulase test was done to detect Staph aureus as described by Baker and Silverton, 1985.

\section{COLLECTION OF SAMPLES FOR TESTS}

Obtain $5.0 \mathrm{ml}$ of blood samples from the apparently healthy subject, confirmed typhoid subjects into a clean glass test tube and place the tubes containing the clotted blood samples for centrifugation and remove serum into another tube without delay.

Sterile bottles with screw caps were used to collect urine and stool from the control and test groups for culturing and identification of bacterial pathogens in both the cassava juice and the stool and urine samples of all the groups. All the tests were done with extreme care so as to get the most considerable result.

Results obtained were represented in figures using histograms.

\section{Results:-}

FIGURE 1: Percentage occurrence of- virulent pathogens in African salad hawked by road-side food vendors. Salmonella organisms rates highest (80\%), shigella (70\%), E. histolytica (50\%), Staph aures (30\%). 


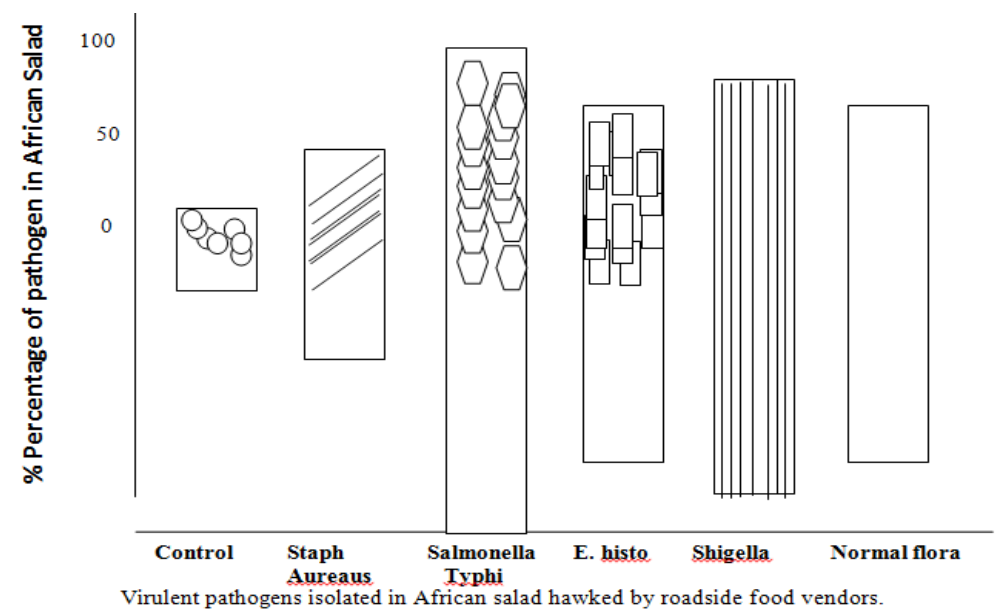

Figure 2: The figure shows the percentage occurrence of the organism Salmonella typhi contracted by the high consumers in various age range compared with their corresponding controls. Group D subjects $(80 \%)$ are most prone to salmonella organisms followed by Group C subjects (70\%) and then Group B subjects (40\%) who eats the delicacy once in a while.

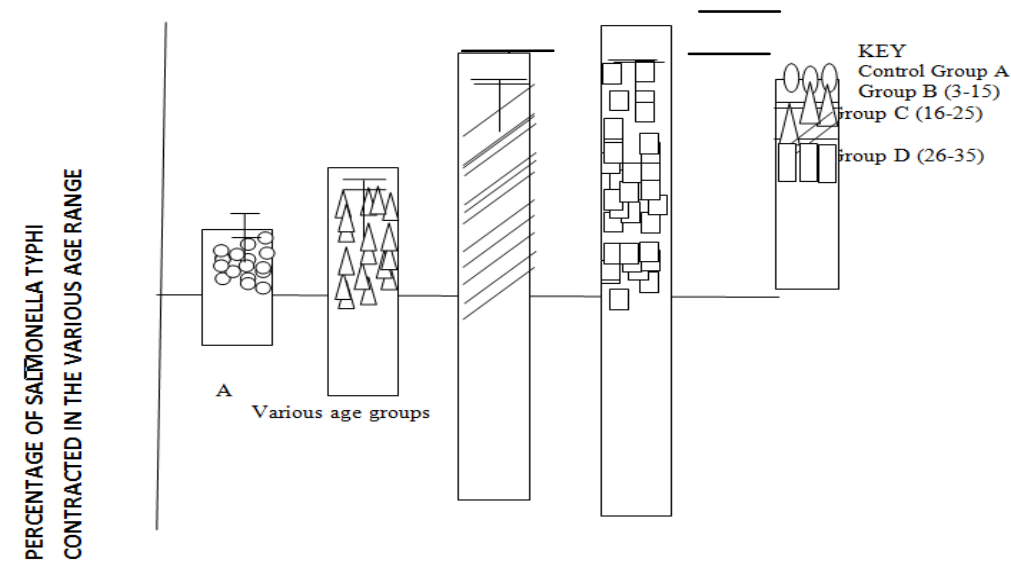

FIGURE 3:Percentage occurrence of Staph. aureus contracted by the high consumers of African Salad in various age groups compared with their corresponding control. The results in the graph shows that staph aureus occurs highest in subjects ( $80 \% 0$ who are chronis consumers, followed by subjects in Group C (70\%), Group B (40\%) and virtually absent in the control subjects (Group A).

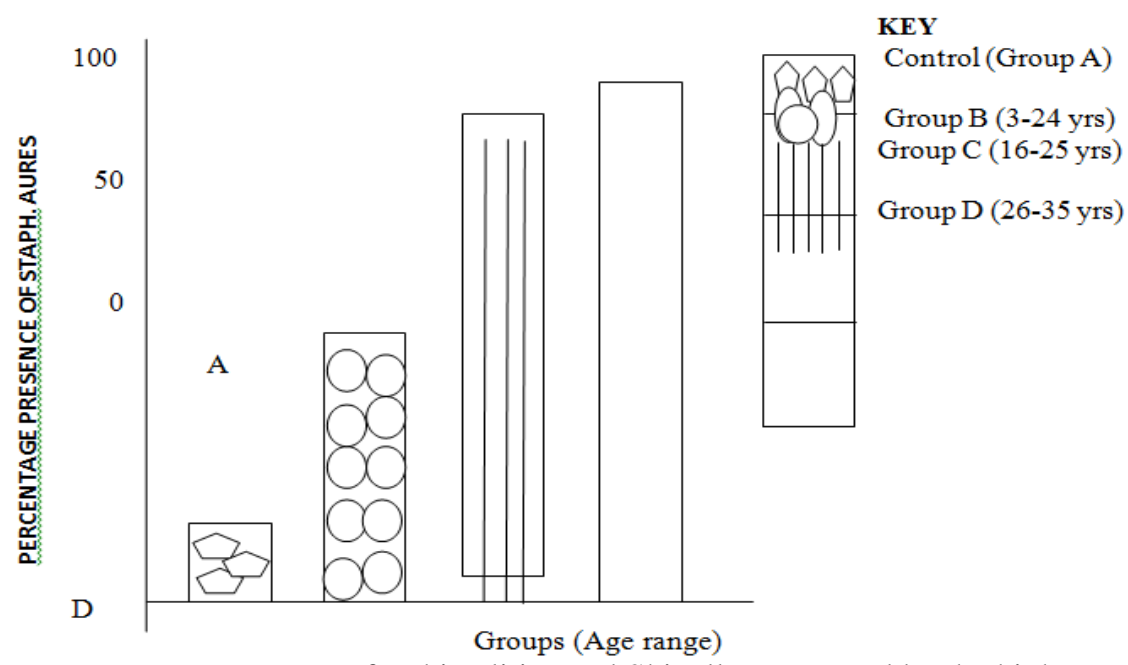

FIGURE 4: $\quad$ Percentage occurrence of E. histolitica and Shigella contracted by the high consumers in various age range compared with their corresponding control who do not often consume it. E. histolytica occurs 
more in Group D subjects (90\%), Group C subjects (80\%) and then Group B (40\%). Shigella organisms occurs more in group C subjects (60\%), followed by Group D subjects (52\%), Group B (40\%).

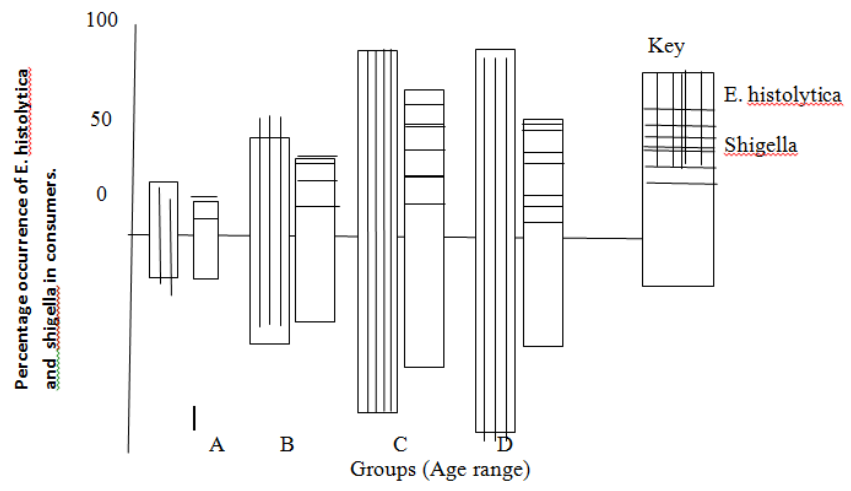

\section{Discussion}

The extent of bacterial contamination of African salad distributed by roadside food vendors in our region have been studied. This African salad delicacy is highly consumed in our region and it is a popular staple food among the poor and rich in our communities. In some regions of Igbo land African salad hawking is the main occupation among women of low-income group.

Then result showed that the percentage of salmonella typhi is highest $(80 \%)$ in the delicacy $\mathrm{p}<0.05$ in figure 1 , shigella $70 \%$, E. histolytica $50 \%$ and staph aureus $30 \%$. The method of keeping the sliced cassava tubers in the stream for 2 days before washing (Ucheonye, 2012) maybe contributing to the high contamination of the cassava with salmonella organisms. The streams are food source of salmonella (Bello 1994) and other waterborne pathogens. The result in figure 2 and 3 indicated that Staph. aureus occur more in group D (26-35 years) and Group C (16-25 years) individual who consumes the African salad delicacy more often while in figure 4, it is mainly E. histolytica that occurs mainly in Groups C and D who also consumes the delicacy more often.

Salmonella pathogen affects the gastrointestinal system by causing diarrhea during the second week of the infection. The patient passes small watery stools at frequent. It is very offensive and may contain blood (Bello, 1994). Vomiting also appears and may be troublesome, the swelling of the belly appears towards the second week. This signifies that the intestines are becoming paralyzed. Bleeding of the intestine is a rare thing in typhoid. It occurs in $3^{\text {rd }}$ week. The patient will occasionally pass stool with blood in it. Perforation of the intestine is also uncommon in typhoid disease. One or more of ulcers perforate with result that the dirty and dangerous stuff inside the intestines is poured out into the cavity of belly.

The result is peritonitis and some may die of this peritonitis; causes of death in typhoid are paralysis of the intestines called ileaus and bleeding.

Entamoeba histolytica when present in the gut system in large quantities due to ingestion of unhygenically prepared African salad causes amoebic dysentery of the gut.

Dysentery results from bacterial infections, or viral infections or parasitic infestations. These pathogens typically reach the large intestines after entering orally through ingestion of contaminated objects or hands (Wikipedia, 2013). The amoebas are able to burrow into the walls of the intestines and cause small abscesses and ulcers to form resulting to frequent passage of slimy stool with blood sometimes mucus and fluids.

In extreme cases, dysentery patients may pass over 2 pints of fluids an hour. More often individuals will complain of nausea, abdominal pain and frequent watery and usually foul smelling diarrhea, accompanied by mucus and blood, rectal pain and fever. Vomiting, weight loss and generalized muscle ache and are also the resultant effect. The sliced cassava tubers used in preparing African salad if they will be washed with clean water (not in the streams) and all the materials such as leaves, animal skin etc used in its preparation are aseptically washed in clean drinking water, it will be free from contamination with pathogens.

Manihot esculenta contains carbohydrate, sugar, water and fibers as mentioned earlier in its chemical contents. Carbohydrates obtained by consumers in a hygienically prepared African salad give energy. They are simple molecules in the cassava and some foods we eat that are broken down by digestion by addition of water into simple sugars. This is as a result of action of enzymes. The research also revealed that African salad contains starch. Pancreatic juice like bile is alkaline. It contains three enzymes: pancreatic amylase which splits starch; the amylase acts on any starch that has escaped the action of ptyalin, including any uncooked starch (as in African salad). Amylases (sucrose, lactase and maltase) split up sucrose, lactose and maltose respectively into the simple sugar glucose (Samuel et al, 1989). In man and some other mammals, such as dog and cat, cellulose is not digested, but in plant eaters cellulose is digested with the help of bacteria and some of the products 
(sugars) are absorbed. Water contained in African salad plays a very important role in digestion. Water is an inorganic substance, but does not yield energy yet it is extremely vital to the body. Water is found in Manihot esculenta, when eat African salad, the water in it replaces the ones we lost through sweating, respiration, preparation and urinating.

Water is a very important part of protoplasm and cells in our body are bathed by a watery liquid. When water is lost from the body in excess quantities as in the disease cholera, amoeboid dysentery (due to consumption of unhygenically processed cassava slices), the person is dehydrated. The fluid part of the blood is plasma and it contains about $91-92 \%$ of water (Samuel et al, 1989). It helps in the transport of nutrients, wastes, gases and hormones. Water lost in sweat helps to regulate the body temperature by making use heat for the evaporation of water from the surface of the skin.

\section{References}

[1]. BAKER F.J, SILVERTON R.E (1985): Plate inoculation methods. Introduction methods. Introduction to medical lab technology pg 263-280.

[2]. BELLO C.S.S(1994): Enteric fever in Jos, Nigeria. Nig. Med. Practitioner 27 No 51995.

[3]. CREWE W.C (19".77). "Examination of faeces for protozoa". A guide to human parasitology for medical practitioners pg 177-181. Published by H.K Lewis and co LTD. 136 Gower street London.

[4]. DESSE G, TAYE M (2007). "Microbial load and microflora of cassava (Manihot esculentun crantz) and effect of cassava juice on some food borne pathogens. Debub University Awassa college of Agriculture. P.O BOX 5 Awassa Ethopia.

[5]. Food safety Network, 2005. www.foodsafetynetwork.com.

[6]. NWEKE F.I (1996). "Cassava processing in subsahara Africa. Implications for expanding cassava production.IITA Research International Institute of Tropical Agriculture.

[7]. SAMUEL P.S, FASUYI O. C, NJOKU P. A (1989). 'Digestion' A new tropical Health Science pg 425. Published by Macmillian Publishers ltd" London ISBN 0333449290.

[8]. UCHEONYE N (2012). How to prepare African salad or Abacha. The Eastern Citadel. http//zymolink.blogspot.com 2012.

[9]. Wikipedia the free encyclopedia (2012). 